\title{
Avaliação do Impacto dos Sistemas ERP sobre Variáveis Estratégicas de Grandes Empresas no Brasil
}

\author{
Amarolinda Zanela Saccol \\ Cristiane Drebes Pedron \\ Guilherme Liberali Neto \\ Marie Anne Macadar \\ Silvio César Cazella
}

\begin{abstract}
Resumo
O artigo apresenta os resultados de uma pesquisa survey realizada numa amostra das 500 melhores e maiores empresas do Brasil, de acordo com a classificação da Revista Exame (2000). A pesquisa procurou avaliar o impacto da utilização dos sistemas ERP (Enterprise Resource Planning) ou Sistemas Integrados de Gestão, sobre as variáveis estratégicas dessas organizações. O instrumento de coleta de dados é uma adaptação do original criado por Mahmood e Soon (1991), para avaliação do impacto da Tecnologia da Informação. Foram avaliadas sete principais variáveis estratégicas: Clientes e Consumidores; Rivalidade Competitiva; Fornecedores; Mercado; Produção; Eficiência e Eficácia da organização e Eficiência interorganizacional. Os resultados revelam poucas contribuições do sistema quanto às variáveis estratégicas Clientes e Consumidores, Rivalidade Competitiva e Mercado. O ERP demonstra agregar valor em relação à variável Fornecedores (relação, monitoramento etc.) e à variável Produção (ganhos de produtividade, escala no uso de software etc.). O ERP oferece também importantes contribuições para a Eficácia Organizacional e especialmente para a Eficiência Interorganizacional, facilitando a integração e comunicação entre diferentes unidades organizacionais e com outras organizações.
\end{abstract}

Palavras-chaves: ERP (enterprise resource planning); impacto da tecnologia da informação; variáveis estratégicas da organização.

\begin{abstract}
The article presents results from a survey in a sample of 70 out of the 500 best and biggest companies in Brazil according to Exame Magazine (2000). The research tried to evaluate the impact of ERP (Enterprise Resource Planning) systems on organizational strategic variables of those companies. The survey instrument adapts Mahmood and Soon's (1991) original model, which is aimed at evaluating the impact of Information Technology on such variables. The study measured 7 strategically important organizational variables: Buyers and Consumers; Competitive Rivalry; Suppliers; Market; Economics of Production; Internal Organizational Efficiency/Effectiveness and Inter-organizational Efficiency. The results reveal only a few contributions of ERP systems regarding the following organizational strategic variables: Buyers and Consumers, Competitive Rivalry, and Market. The ERP contributes to the Suppliers variable (relationship, monitoring etc.) and to the Production variable (productivity gains, economies of scale in software usage etc.). The ERP also contributes to the Internal Organizational Efficiency, and specially to the Inter-organizational Efficiency, improving the integration and communication between organizational units and with other organizations.
\end{abstract}

Key words: enterprise resource planning; information technology impact; organizational strategic variables. 


\section{INTRODUÇÃO}

Os sistemas ERP (Enterprise Resource Planning), também conhecidos como Sistemas Integrados de Gestão, são uma das tecnologias mais utilizadas e discutidas na área de Sistemas de Informação, nos últimos anos. O mercado de sistemas ERP faturou, em 2002, cerca de U\$S 5 bilhões somente com a venda de licenças (Bloomberg News, 2003), muito embora ele esteja em retração, tendo apresentado uma queda de 9\% no faturamento de 2001 para 2002. Tendências nesse setor apontam para mudanças nos portfólios de produtos oferecidos, fusão de fornecedores de pacotes e sua expansão no segmento das médias e pequenas empresas, oferecendo-se a promessa de metodologias de implantação rápida (Barros, 2003; Mesquita, 2003; Gobara, 2003).

Essas tendências contemplam mudanças no comportamento dos compradores, que se tornaram mais cautelosos, devido em grande parte a experiências de implantação de ERPs que não cumpriram o prometido (Bloomberg News, 2003). Nesse sentido, apesar de se contar com diversas pesquisas a respeito dos sistemas ERP, poucos são os estudos que se propõem a avaliar os resultados obtidos com a sua utilização. A maioria das pesquisas foca o ciclo de vida do sistema, especialmente a etapa de implantação (Esteves e Pastor, 2001), ou avaliam resultados genéricos, sem foco nos elementos estratégicos. Como exemplo disso, Delloite Consulting (1998) e Bernroider e Koch (1999) apontaram alguns dos principais resultados esperados com a adoção de sistemas ERP, tais como melhoria da qualidade e visibilidade da informação, maior integração e melhoria dos processos organizacionais, reduções de pessoal e reduções de inventário. Notese que o foco dessas pesquisas recai mais sobre atividades-meios e recursos internos, deixando de lado diversos aspectos de caráter mais estratégico. Davenport (2000) aponta que um dos tópicos menos visados nos sistemas ERP consiste justamente em analisar as implicações da sua adoção para a estratégia organizacional, assim como para a estrutura e a cultura organizacional.

Assim, visando a oferecer uma contribuição nessa lacuna, este artigo apresenta os resultados de uma pesquisa survey realizada numa amostra das 500 melhores e maiores empresas do Brasil, de acordo com a classificação da Revista Exame (2000), a respeito do impacto dos sistemas ERP sobre variáveis estratégicas da organização.

Alguns autores como Hedman e Borell (2002) e Sedera, Gable e Chan (2003) destacam a importância de se avaliar o impacto dos sistemas ERP sobre a 
efetividade organizacional; contudo apontam uma série de fatores que tornam difícil essa avaliação, especialmente a complexidade e a abrangência dos sistemas ERP. Considerando essas dificuldades, neste estudo optou-se pela adaptação de um modelo de avaliação de impacto de Tecnologia de Informação (TI), já validado e consagrado, para avaliação do impacto dos sistemas ERP: o instrumento proposto por Mahmood e Soon (1991).

Na seqüência, faz-se um apanhado dos conceitos inerentes ao estudo. Logo após, é apresentado o seu método de pesquisa. A seguir, os resultados encontrados são apresentados e discutidos. Por fim, são feitas considerações finais e indicações de pesquisas futuras.

\section{Impacto da Tecnologia da Informação sobre a Estratégia Organizacional}

A aplicação da TI pode trazer ganhos significativos a uma organização, mas a escolha e seleção da tecnologia adequada dependem de profundo entendimento das estratégias adotadas pela empresa e das conseqüências desta escolha sobre as variáveis estratégicas (Parsons, 1983). A não observância do alinhamento entre estratégia e tecnologia pode ocasionar impacto negativo, com perda de recursos e desgaste humano. Luftman, Lewis e Oldach (1993) afirmam que a TI, isoladamente, não representa vantagem competitiva a longo prazo, pois ela pode, muitas vezes, ser facilmente imitável. Da mesma forma, Hitt e Bryjolfsson (1996) apontam que, embora as empresas possam aumentar a produtividade e o valor para os clientes com adoção de TI, não necessariamente irão obter maior lucratividade.

No entanto há o outro lado: se uma empresa deixa de adotar uma TI já utilizada pelos seus competidores, estará em situação de desvantagem competitiva, por não ter uma competência que passa a ser exigida. Esse parece ser o caso dos sistemas ERP. De acordo com Kumar e Hillegersberg (2000, p. 24), esses sistemas são hoje considerados, no mínimo, “o preço de entrada para se realizar negócios”. Torna-se, portanto, instigante avaliar quais variáveis estratégicas eles poderão de fato impactar, pois sua utilização poderá viabilizar uma série de modificações e adaptações na empresa.

Fortemente influenciados por Porter (1980), Bakos e Treacy (1986), distinguiram três níveis nos quais a TI colabora com a estratégia corporativa: os níveis interno, competitivo e de portfólio de negócio. O primeiro relaciona-se com o desenvolvimento da eficiência e eficácia das estruturas e processos organizacionais 
para atingir objetivos e metas traçados. Melhorar a eficiência e eficácia organizacional é o domínio tradicional da TI. Já o nível de Estratégia Competitiva foca em movimentos competitivos dentro da indústria pelos quais a organização realiza seus negócios. O nível de Estratégia de Portfólio de Negócios diz respeito às escolhas pelas quais as empresas competem para se posicionar na sua respectiva indústria. Essa visão ampla do impacto da TI na estratégia corporativa (níveis interno, competitivo e de portfólio de negócios) é a visão considerada neste trabalho.

De maneira semelhante, Parsons (1983) apresentou um modelo multinível para avaliar o impacto competitivo da TI. Ele apresenta três níveis pelos quais a TI pode afetar uma empresa: Nível de Indústria (pode mudar em uma indústria, produtos e serviços, mercados e economia de produção); Nível da Firma (afeta forças competitivas, como compradores, fornecedores, substitutos, novos entrantes e rivalidade) e Nível Estratégico (afeta as estratégias de liderança de baixo custo, diferenciação de produtos e concentração em nicho específico de mercado ou produto).

Clemons (1987) também utiliza enfoque porteriano para pensar o impacto da TI sobre a vantagem competitiva (nível estratégico), distinguindo o uso da TI quanto ao enfoque interno (eficiência organizacional) e externo (geração de valor agregado para o consumidor).

O modelo de avaliação do impacto da TI adotado. Como pode ser visto, a literatura existente propõe uma série de frameworks para identificar oportunidades de uso estratégico da TI. Entretanto, Mahmood e Soon (1991) alegam que estes frameworks ou vigamentos não constituem uma colaboração expressiva para a compreensão do potencial de uso da TI como arma estratégica ou de competitividade. Isso, segundo os autores, se deve ao fato de que estes frameworks não foram empiricamente testados, e não há modelos explanatórios derivados deles, entre outras razões. Motivados por esse contexto, Mahmood e Soon conduziram um estudo tendo como base as 500 maiores empresas americanas, com o objetivo de construir e testar empiricamente um modelo para avaliação do impacto da TI nas variáveis estratégicas das empresas. Para a construção da versão inicial do modelo, eles se basearam, entre outros, nos frameworks propostos por Mc Farlan (1984); Parsons (1983); Bakos e Treacy (1986) e Cash e Konsynski (1985). As variáveis encontradas na literatura foram avaliadas por gestores de negócio; estes indicaram quais variáveis estratégicas de fato podem ser impactadas pela TI (de forma genérica, sem considerar uma tecnologia específica). Isso resultou na proposição e disponibilização de um modelo de avaliação do impacto da TI nas organizações. As 10 variáveis estratégicas apontadas pelo modelo são: Compradores e Consumidores; Produtos e Serviços; 
Rivalidade Competitiva; Economia de produção; Estrutura de Custo e Capacidade; Fornecedores; Eficiência Interna da Organização; Custo de Busca e Custo de Mudança; Eficiência Interorganizacional; Mercado e Formação de Preço. Esse modelo foi o escolhido para a realização da pesquisa aqui apresentada, devido à sua abrangência, flexibilidade e ao rigoroso trabalho de teste e validação realizado sobre ele.

\section{SISTEMAS ERP}

Diversas são as pesquisas acadêmicas realizadas sobre os sistemas ERP na área de gestão, no Brasil, especialmente desde 1999. Entre elas destacam-se as referências de Caldas e Wood (1999); Wood e Caldas (2000); Neves (1999); Bergamaschi e Reinhard (2000); Souza e Zwicker (2000, 2001, 2002); Hypolito e Pamplona (2000); Saccol, Macadar e Soares (2001) e Mendes e Escrivão Filho (2001). Souza e Saccol (2003) organizaram uma coletânea que reúne diversas pesquisas sobre ERP no Brasil. Boa parte dessas pesquisas trata dos processos de implantação, mudança e resultados obtidos com a utilização dos sistemas ERP de forma geral. Em nível internacional, Esteves e Pastor (2001) realizaram uma análise da literatura existente a respeito desses sistemas, indicando diversas referências.

Assim, não cabe retomar todos os conceitos básicos inerentes a essa tecnologia. Cabe, porém, definir o que se entende por ERP no contexto desta pesquisa. Davenport (2000) define os sistemas ERP como pacotes de aplicações computacionais que dão suporte à maior parte das necessidades de informação das organizações, sendo derivado dos sistemas MRP (Manufacturing Resource Planning). O ERP se diferencia dos demais sistemas pela integração das informações da empresa, por meio do uso de um banco de dados único para toda a organização. Ele é composto de módulos integrados que atendem a cada área funcional ou processo, como Finanças, Produção, Custos, Vendas, RH etc.

Ainda assim, cabe fazer uma ressalva, lembrando que (como será visto na seqüência) algumas das empresas pesquisadas desenvolveram seus sistemas integrados internamente, ou tiveram módulos desenvolvidos internamente, sendo utilizados paralelamente aos pacotes comerciais de ERP, assim como algumas delas possuem até 3 diferentes pacotes ERP (de diferentes fornecedores), utilizados simultaneamente. De acordo com Kumar e Hillegersberg (2000), muitas empresas podem adotar a estratégia de componentização, adotando uma espinhadorsal mínima de poucos fornecedores de pacotes ERP, e a ela agregando outros componentes ou módulos para atender às suas necessidades específicas. 


\section{Metodologia de Pesquisa}

Considerando seu objetivo, avaliar o impacto da utilização dos sistemas ERP sobre variáveis estratégicas em empresas brasileiras, a pesquisa teve caráter descritivo. O método utilizado foi a pesquisa survey (Fink, 1995), tendo como população-alvo as 500 maiores e melhores empresas do país, segundo Revista Exame (2000). Os respondentes da pesquisa foram gerentes e diretores da área de TI e Sistemas de Informação das empresas pesquisadas (um respondente em cada organização). A pesquisa foi desenvolvida em duas etapas. Na primeira etapa foi realizada uma pesquisa exploratória, para se conhecer e dimensionar a amostra. O objetivo foi o de descobrir, entre as 500 Maiores e Melhores, aquelas empresas que possuíam um sistema ERP e que tinham alguma experiência na sua utilização. Na segunda etapa foi aplicado o questionário de pesquisa propriamente dito.

Primeira Etapa: Pesquisa Exploratória. Primeiramente, a pesquisa exploratória buscou conhecer e dimensionar a amostra (via telefone) para identificar, entre as 500 empresas, as que possuíam um ERP. Assim, a amostra obtida não foi aleatória, mas sim escolhida pelo critério de conveniência (Fink, 1995). Buscou-se também investigar nessas empresas o tempo de utilização do ERP, o seu fornecedor, bem como os dados do gerente ou diretor de informática para a futura aplicação da survey. Essa etapa teve duração de 4 meses. Utilizou-se um roteiro estruturado para o questionamento das empresas pesquisadas. Os resultados dessa etapa podem ser visualizados no Quadro 1.

\section{Quadro 1: Resultados da pesquisa exploratória das 500 Melhores e Maiores}

\begin{tabular}{|l|c|}
\hline \multicolumn{1}{|c|}{ RESULTADO } & NÚMERO DE EMPRESAS \\
\hline Possuem ERP & 209 \\
\hline Não possuem ERP & 15 \\
\hline Não responderam & 150 \\
\hline $\begin{array}{l}\text { Não foram contatadas por dados de contato } \\
\text { incorretos }\end{array}$ TOTAL & 126 \\
\hline \multicolumn{1}{|c|}{ T00 } \\
\hline
\end{tabular}

Como se pode observar, o acesso às organizações foi dificultado pelo número significativo de empresas que não desejaram participar da pesquisa (150), bem como várias empresas não puderam ser contatadas, em face dos erros nos dados de contato publicados (126). Por fim, ficou claro que a pesquisa deveria ser 
aplicada às 209 empresas contatadas que utilizavam o ERP e que se dispuseram a participar dela.

Instrumento de pesquisa: adaptação e validação. Paralelamente à realização da pesquisa exploratória, foi-se adaptando o instrumento criado e validado por Mahmood e Soon (1991), para a realização da pesquisa descritiva. O questionário original era composto por 50 questões em escala Likert (1 a 5 - Discordo plenamente a Concordo plenamente), com afirmações sobre o impacto da TI sobre variáveis estratégicas. Primeiramente, todo o instrumento de coleta original foi traduzido para o português. A tradução foi realizada por três pessoas (um nativo da língua inglesa e dois brasileiros), separadamente. Na seqüência a equipe de pesquisa definiu, questão por questão, qual seria a tradução mais correta, observando-se a qualidade dos termos técnicos utilizados. Após a tradução, o instrumento foi avaliado por uma comissão de especialistas, formada por dois conceituados pesquisadores da área de Sistemas de Informação, quanto à sua validade de face (Fink, 1995).

Na seqüência foram realizados dois testes pilotos, em duas diferentes turmas de cursos de especialização na área de TI no sul do País. Os respondentes foram 26 executivos de nível estratégico de organizações gaúchas. Tendo em vista os resultados desses dois pré-testes, percebeu-se que o ponto frágil do instrumento de pesquisa era o grande número de questões (50 no total) de forma idêntica ao questionário original elaborado por Mahmood e Soon (1991). Com isso, foi necessária nova adaptação do instrumento e reavaliação da relevância de cada questão, até se chegar ao questionário definitivo, composto por 34 questões. Dos 10 blocos de questões originais foram selecionados 7. O critério de eliminação dos blocos e questões foi a redundância de algumas delas para os objetivos da pesquisa, ou a maior dificuldade de entendimento das diferentes terminologias de negócio do idioma original para o português, dificuldades estas identificadas durante o pré-teste.

Segunda etapa: aplicação do questionário da Pesquisa Descritiva. Uma vez que o instrumento de pesquisa foi testado e validado, foi criado um website para coleta de dados. A segurança dos dados foi garantida mediante senhas para o acesso individual e exclusivo de cada respondente previamente identificado na primeira etapa da pesquisa (exploratória). Essa senha foi encaminhada à amostra pré-selecionada, composta de 209 empresas, por e-mail, que apresentava os objetivos da pesquisa e indicava o link de acesso ao questionário. Após o preenchimento do questionário, o respondente tornava-se impossibilitado de voltar a respondê-lo, o que garantiu a confiabilidade dos dados.

Após o envio do primeiro e-mail que apresentava a pesquisa, obteve-se um retorno de 11 questionários respondidos. Na seqüência, foram enviadas mais 
4 mensagens eletrônicas aos não-respondentes, convidando-os a participar da pesquisa. A cada contato (com um intervalo de cerca de 15 dias) retornavam em média cerca de 12 questionários preenchidos. Junto à última mensagem eletrônica foi encaminhado o questionário em documento no formato Microsoft ${ }^{\mathrm{tm}}$ Word, além do endereço de acesso à página Web. Cinco respondentes preferiram utilizar o arquivo anexado para responder ao questionário, ao invés da Web. A coleta de dados, que havia iniciado em setembro de 2001, estendeu-se até janeiro de 2002.

Houve dificuldade na coleta dos dados, pois a amostra consistia em algumas das Melhores e Maiores empresas do país, grupo de organizações bastante acessado para aplicação de pesquisas sobre os mais diversos assuntos de Administração. Uma vez coletados os dados, com retorno de 70 empresas entre as 209 contatadas, estes foram tratados estatisticamente e são apresentados na seqüência.

\section{Apresentação dos Resultados}

Nesta seção apresentam-se os dados coletados e os principais resultados da pesquisa (veja também Saccol et al., 2003).

\section{Perfil da Amostra}

Como já tratado anteriormente, a amostra final é composta por 70 das 500 melhores e maiores empresas brasileiras de acordo com a classificação de Revista Exame (2000). Por ser uma amostra não probabilística, os resultados aqui apresentados referem-se às 70 empresas investigadas. A maior parte delas pertence ao setor industrial (70\%); seguido do setor Comércio (20\%) e Serviços (10\%). Apesar de as empresas industriais prevalecerem na amostra, há grande variedade de subsetores aos quais elas pertencem, como pode ser visualizado no Quadro 2. Entre os principais setores estão o de Atacado e Comércio Exterior, Siderurgia e Metalurgia, Química e Petroquímica e Alimentos. Quanto ao tamanho, 42,9\% das empresas tem entre 1000 a 3000 funcionários (vide Figura 1). 20\% tem entre 3000 a 5000 funcionários, portanto a amostra é composta por grandes corporações. 


\section{Figura 1: Número de Funcionários}

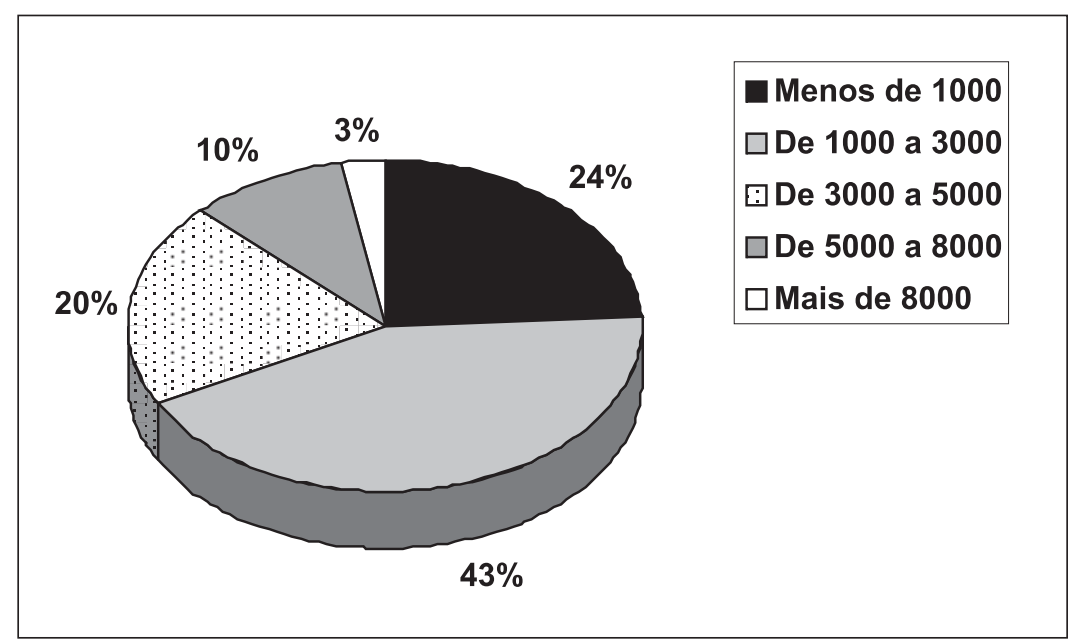

Quanto ao tipo de sistema ERP adotado, 28,4\% (23 empresas) da amostra adotaram o sistema R3 da empresa SAP; $24,7 \%$ possuem módulos desenvolvidos internamente; 7,4\% (6 empresas) possuem Oracle; as demais empresas se dividem em grande variedade de marcas, como JDEdwards, Microsiga, Datasul, Baan, SSA e Peoplesoft. Outros tipos (12, 3\%) incluem ERPs específicos por setor, aqui não identificados para manter o anonimato das empresas pesquisadas. Cabe ressaltar que desde a aplicação da pesquisa, o mercado de pacotes ERP passou por uma concentração de empresas fornecedoras, com diversas fusões e incorporações: entre elas, a Peoplesoft adquiriu a JDEdwards (Bloomberg News, 2003), assim como a SSA incorporou a Baan (Cesar, 2003).

Cabe destacar que 9 das 70 empresas pesquisadas possuem mais de um tipo (marca) de ERP, algumas delas combinando pacotes disponíveis no mercado e módulos desenvolvidos internamente. Duas empresas possuem 3 tipos diferentes de ERP sendo utilizados. Em relação ao tempo de adoção dos sistemas ERP, somente 6 das 70 empresas (8,6\%) utilizam o sistema há menos de 1 ano. A maior parte da amostra (52,9\%) utiliza o ERP há mais de 2 anos, sendo que $24,3 \%$ o utilizam há mais de 5 anos. Tem-se, portanto, um grupo de empresas com boa experiência no uso do sistema estudado. 


\section{Quadro 2: Setor - Empresas Pesquisadas}

\begin{tabular}{|l|l|l|}
\hline SETOR & QTD & FREQ \\
\hline Atacado e Comércio Exterior & 9 & $12.9 \%$ \\
\hline Siderurgia e Metalurgia & 7 & $10.0 \%$ \\
\hline Química e Protroquímica & 7 & $10.0 \%$ \\
\hline Alimentos & 6 & $8.6 \%$ \\
\hline Eletroeletrônico & 5 & $7.1 \%$ \\
\hline Comércio Varejista & 5 & $7.1 \%$ \\
\hline Automotivo & 4 & $5.7 \%$ \\
\hline Confecções e Têxteis & 4 & $5.7 \%$ \\
\hline Papel e Celulose & 3 & $4.3 \%$ \\
\hline Mecânica & 3 & $4.3 \%$ \\
\hline Tecnologia e Computação & 3 & $4.3 \%$ \\
\hline Serviços diversos & 3 & $4.3 \%$ \\
\hline Material de Construção & 2 & $2.9 \%$ \\
\hline Bebidas & 2 & $2.9 \%$ \\
\hline Farmacêutica & 2 & $2.9 \%$ \\
\hline Outros & 5 & $7 \%$ \\
\hline TOTAL CIT. & 70 & $100 \%$ \\
\hline
\end{tabular}

Figura 2: Tipos de ERPs Utilizados pelas Empresas Pesquisadas

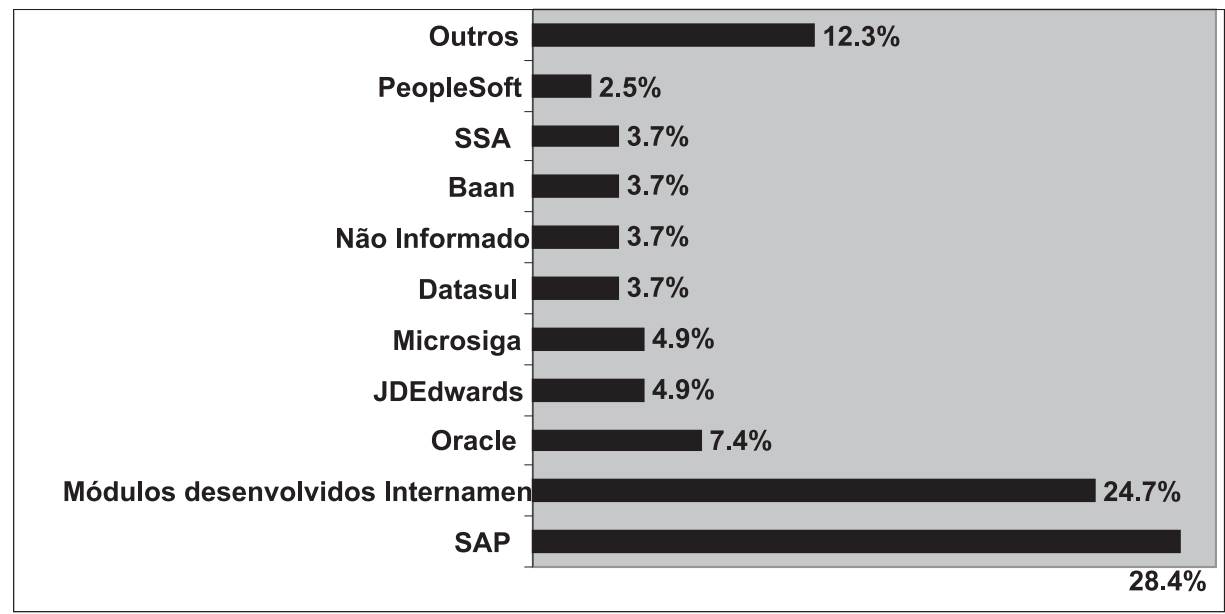




\section{Avaliação do Impacto do ERP sobre Variáveis Estratégicas nas Empresas Pesquisadas}

Para melhor análise dos dados, os resultados são apresentados de acordo com os 7 blocos de questões levantadas. Cada um deles corresponde a uma das variáveis estratégicas apontadas por Mahmood e Soon (1991): Clientes e Consumidores; Rivalidade Competitiva; Fornecedores; Mercado; Produção (estrutura de custo e capacidade); Eficiência e Eficácia organizacional e Eficiência interorganizacional.

Bloco 1 - Clientes e Consumidores. Sobre a contribuição do ERP para o relacionamento da empresa com clientes e consumidores, destaca-se primeiramente que somente $27,2 \%$ dos respondentes concordaram com o fato de que o ERP disponibiliza informações sobre serviços e produtos aos consumidores; $42,9 \%$ discordam dessa afirmativa; e $28,6 \%$ se mostraram indiferentes a ela.

Caberia realizar-se um estudo para investigar se isso diz respeito à forma como o ERP é utilizado na empresa. Por exemplo, se utilizado como a plataforma para a realização de $e$-business, essa ferramenta pode ser fundamental para tornar disponível informações sobre a empresa aos consumidores (Shields, 2001). Entretanto a maioria dos respondentes (87,1\%) concordam em que o ERP ajuda a empresa a prover suporte administrativo aos clientes (como faturamento, cobrança, gestão de estoques). Nesse sentido, o ERP contribui estrategicamente para a melhoria das relações com os clientes da organização.

Bloco 2 - Rivalidade Competitiva. Neste bloco de questões se buscou levantar até que ponto o ERP contribui para uma investida contra os competidores da empresa, seja por ajudar a oferecer um produto/serviço que os competidores não consigam igualar, seja por ajudar a prover produtos/serviços substitutos antes que os competidores o façam.

Os respondentes se dividiram quanto à questão que trata da contribuição do ERP para a empresa realizar a primeira investida contra competidores: 37,2\% tendem a discordar dessa afirmativa; 31,4\% concordam e 30\% mostram-se indiferentes. Os respondentes novamente se mostraram indiferentes quando à questão que envolve o uso de ERP para fazer frente à concorrência (contribuindo para criação de produtos substitutos). O sistema não é visto como facilitador das ações da empresa no processo concorrencial por 37,2\% dos respondentes. Portanto não foi indicada uma contribuição significativa do ERP para a rivalidade competitiva da empresa. 
Bloco 3 - Fornecedores. Neste bloco foi possível identificar uma das principais contribuições dos sistemas ERP, como facilitador da relação empresafornecedores.

Entre os respondentes, 51,4\% concordam que o ERP colabora para o aumento do poder de barganha da empresa junto aos seus fornecedores (vide Quadro 3). O ERP se mostrou também como recurso que ajuda a reduzir a incerteza de lead time. Lead time é o tempo que decorre entre a liberação de uma ordem (de compra ou produção) e o momento a partir do qual o material referente à ordem está pronto e disponível para uso (Corrêa, Gianesi e Caon, 1999). Neste sentido, $67,2 \%$ dos respondentes concordam que o ERP ajuda a reduzir a incerteza de lead time. Isso com certeza se deve às informações em tempo real, providas pelo sistema. Os respondentes apontaram outra contribuição do ERP, quando 68,6\% deles concordaram que essa ferramenta também ajuda a empresa a encontrar novas alternativas de fornecedores. Da mesma forma, os respondentes, em sua maioria (67,2\%), concordaram que o ERP ajuda nas decisões relativas a produzir x comprar determinado insumo; 70\% dos respondentes também concordam que o ERP ajuda a monitorar a qualidade dos produtos e serviços recebidos dos fornecedores (vide Quadro 4).

\section{Quadro 3: Poder de Barganha frente a Fornecedores}

\begin{tabular}{|l|l|l|}
\hline Barganha c/ fornecedores & Qt. cit. & Freq. \\
\hline Não resposta & 1 & $1.4 \%$ \\
\hline Discordo Totalmente & 4 & $5.7 \%$ \\
\hline Discordo & 8 & $11.4 \%$ \\
\hline Indiferente & 21 & $30.0 \%$ \\
\hline Concordo & 25 & $35.7 \%$ \\
\hline Concordo Totalmente & 11 & $15.7 \%$ \\
\hline TOTAL OBS. & 70 & $100 \%$ \\
\hline
\end{tabular}

Quadro 4: Monitoramento - Fornecedores

\begin{tabular}{|l|l|l|}
\hline Monitor. fornecedores & Qt. cit. & Freq. \\
\hline Discordo Totalmente & 2 & $2.9 \%$ \\
\hline Discordo & 4 & $5.7 \%$ \\
\hline Indiferente & 15 & $21.4 \%$ \\
\hline Concordo & 30 & $42.9 \%$ \\
\hline Concordo Totalmente & 19 & $27.1 \%$ \\
\hline TOTAL OBS. & 70 & $100 \%$ \\
\hline
\end{tabular}


Em praticamente todas as questões relativas à variável estratégica Fornecedores, o ERP se apresenta como ferramenta que contribui para o relacionamento, a escolha e o monitoramento destes por parte da empresa que utiliza o sistema.

Bloco 4 - Mercado. O quarto bloco de questões procurou identificar como o ERP impacta a relação da empresa com o seu mercado, de forma geral.

Os respondentes mostraram-se divididos quanto à contribuição do ERP para a previsão das tendências de mercado. Cerca de 30\% deles se estabeleceram em cada categoria de resposta, entre os que discordam, os que são indiferentes e os que concordam que o ERP ofereça alguma contribuição nesse sentido. Porém, se por um lado o ERP não contribui com as previsões de mercado, os respondentes em sua maioria $(61,4 \%)$ concordam que ele contribui para maior precisão na previsão de vendas (vide Figura 3). Entretanto apenas pequeno subgrupo de respondentes (35,7\%) concorda que o ERP ajuda a empresa a antecipar melhor as necessidades dos clientes. Boa parte deles (40\%) mostrase indiferente a essa contribuição, enquanto $24,2 \%$ discordam dela. Os respondentes também se dividem quanto à contribuição do ERP para a lealdade dos clientes, sendo que $38,6 \%$ discordam que ele possa contribuir nesse sentido, e apenas $28,6 \%$ concordam com essa afirmativa; $51,4 \%$ dos respondentes discordam da afirmação de que o ERP ajuda a reduzir custos de marketing na empresa. Pode-se notar que o ERP não se mostra uma ferramenta que contribui significativamente com a variável estratégica Mercado.

Figura 3: ERP x Previsão de Vendas

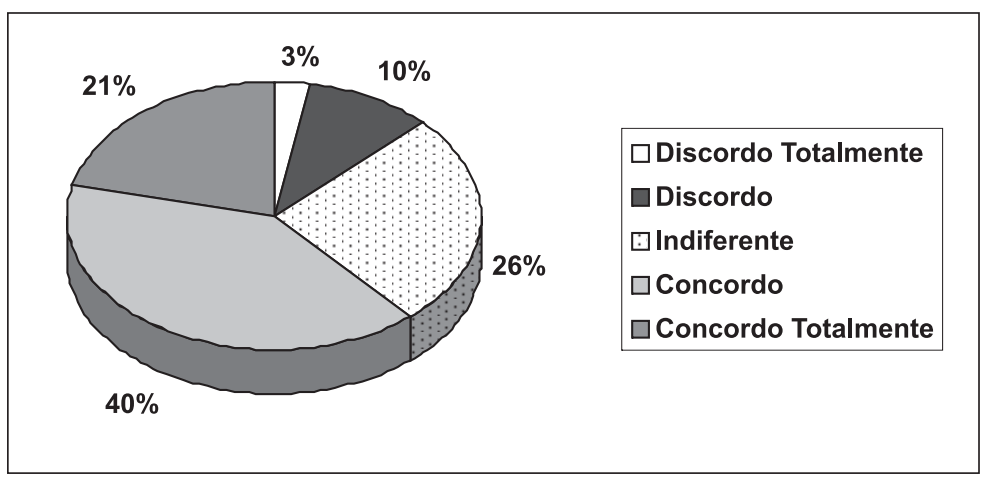

Entretanto, quando questionados sobre a contribuição do ERP para a eficiência competitiva da empresa, 77,2\% dos respondentes concorda que o sistema contribui nesse sentido (vide Quadro 5). 


\section{Quadro 5: ERP x Eficiência Competitiva}

\begin{tabular}{|l|l|l|}
\hline ERP x Efic. Competitiva & Qt. cit. & Freq. \\
\hline Discordo Totalmente & 1 & $1.4 \%$ \\
\hline Discordo & 3 & $4.3 \%$ \\
\hline Indiferente & 12 & $17.1 \%$ \\
\hline Concordo & 34 & $48.6 \%$ \\
\hline Concordo Totalmente & 20 & $28.6 \%$ \\
\hline TOTAL OBS. & 70 & $100 \%$ \\
\hline
\end{tabular}

Assim, conclui-se que, em geral, o ERP não oferece contribuições relevantes à relação da empresa com seu mercado (conhecimento do mercado e do cliente, fidelização etc.). Caberia investigar melhor a percepção dos respondentes sobre a eficiência competitiva, uma vez que, em outras questões (ver bloco Rivalidade Competitiva), o sistema não se mostrou como elemento contribuinte. Talvez ao responder a essa pergunta, os próprios respondentes estejam envolvidos com o discurso geral da mídia sobre a importância dos sistemas ERP. Um exemplo claro desse elemento fica evidenciado na pesquisa de Ranganathan e Samarah (2001). Os autores investigaram o impacto da adoção de um sistema ERP sobre o valor da firma, valor este atribuído pelo mercado de capitais. Os resultados demonstraram valorização das ações acima do comum após as empresas terem anunciado a adoção do sistema no mercado, especialmente no caso de empresas industriais. Isto é, os investidores, nos casos estudados, viram a adoção de um sistema ERP como fator que aumenta o valor de mercado das empresas adotantes.

Bloco 5 - Produção (estrutura de custo e capacidade). Neste bloco se procurou identificar a contribuição do ERP para questões relacionadas à produção da empresa, ao gerenciamento de custos e da capacidade produtiva.

Considerando a atividade de desenvolvimento de novos produtos, quando questionados a respeito do fato de o ERP reduzir o custo de projetar novos produtos/serviços, os respondentes mostram-se divididos, sendo que 41,4\% deles se mostra indiferente a esse impacto do ERP. Da mesma forma, os respondentes se dividem, quando questionados sobre se o ERP contribui para a redução do custo de modificar ou adicionar características aos produtos/ serviços existentes (27,10\% concordam, 40\% mostram-se indiferentes e 32,8\% discordam). Pode-se perceber que o ERP não impacta o processo de desenvolvimento de produtos. Estudos de Hedman e Borell (2002) apontam a fraqueza dos sistemas ERP em relação à flexibilidade, inovação e adaptação nos processos organizacionais. 
Contudo, em relação à produção propriamente dita, os respondentes, em sua grande maioria (74,2\%), concordam com a afirmação de que o ERP ajuda a melhorar o nível de produção (vide Quadro 6).

\section{Quadro 6: ERP ajuda a melhorar o nível de produção}

\begin{tabular}{|l|l|l|}
\hline ERP x Nível Produção & Qt. cit. & Freq. \\
\hline Não resposta & 1 & $1.4 \%$ \\
\hline Discordo Totalmente & 0 & $0.0 \%$ \\
\hline Discordo & 6 & $8.6 \%$ \\
\hline Indiferente & 11 & $15.7 \%$ \\
\hline Concordo & 33 & $47.1 \%$ \\
\hline Concordo Totalmente & 19 & $27.1 \%$ \\
\hline TOTAL OBS. & 70 & $100 \%$ \\
\hline
\end{tabular}

Da mesma forma, boa parte dos respondentes (77,1\%) concorda que o ERP ajuda a melhorar a produtividade do trabalho por meio da automação (vide Figura 4). Hedman e Borell (2002) também identificaram contribuições dos sistemas ERP para a produtividade e controle organizacional, especialmente em relação a processos internos da organização e modelos de metas. $47,1 \%$ dos respondentes também concordam que o ERP contribua para a gestão da produção, por ajudar a melhorar a utilização do maquinário. Entretanto cabe considerar que boa parte deles se mostra indiferente nessa questão (40\%).

\section{Figura 4: ERP Contribui para a Produtividade, por meio da Automação}

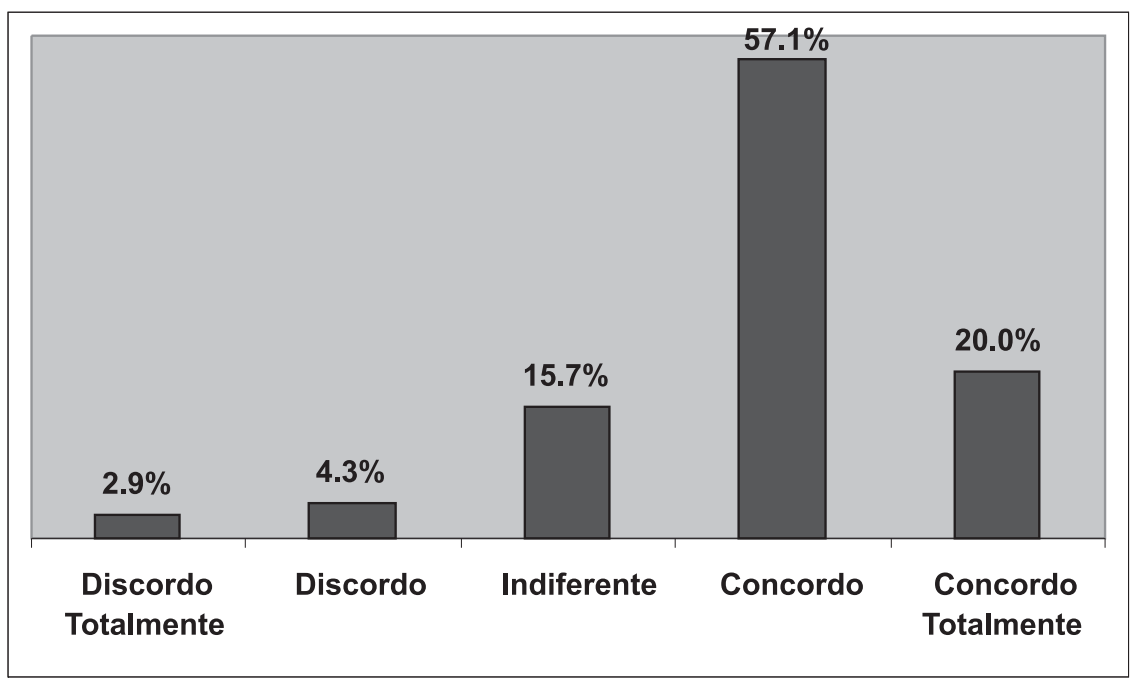


Quanto a ganhos em economia de escala no uso de software, 61,4\% dos respondentes concordam que o ERP contribua nesse sentido. Naturalmente esta é uma das maiores vantagens da adoção de pacotes ERP (lembrando que apenas 20 das 70 empresas possuem ERP/módulos desenvolvidos internamente). Da mesma forma, $47,1 \%$ dos respondentes concordam que o ERP contribui para ganhos de escala no uso de hardware, muito embora cerca de 35\% se mostrem indiferentes nessa contribuição. Portanto o ganho de escala significativo reside no uso de software.

Analisando as questões desse bloco (Produção: estrutura de custo e capacidade) pode-se concluir que o sistema não se mostrou como contribuidor para o processo de desenvolvimento de produtos; mas, de forma geral, contribui com a produtividade da organização, por ganhos de produtividade e de escala em software, e também pela automação de processos decorrente de sua adoção.

Bloco 6 - Eficiência e Eficácia Organizacional. Este bloco procurou avaliar o impacto do ERP sobre a eficiência/eficácia organizacional, especialmente considerando sua contribuição para a gestão organizacional.

A primeira questão levantada procurou sondar se o ERP ajuda a melhorar o processo e o conteúdo das decisões. A grande maioria dos respondentes (88,6\%) afirma que o ERP contribui nesse sentido. Apenas 1 entre os 70 respondentes discorda dessa afirmação.

Da mesma forma, 65,8\% dos respondentes concordam que o ERP melhora as reuniões e discussões internas, o que é importante para a tomada de decisões e eficácia organizacional.

Uma das grandes vantagens de um sistema ERP é a integração organizacional. Isto é confirmado pelos respondentes, que em sua grande maioria (90\%) concordam que o ERP possibilita melhor coordenação entre as áreas funcionais na empresa. Eles também concordam (80\%) que o ERP contribui para melhores avaliações nos relatórios anuais do orçamento, o que melhora a gestão financeira da empresa (vide Figura 5). O ERP também é visto como ferramenta eficaz para o planejamento na organização: 65,7\% dos respondentes concordam que ele ajuda a melhorar o planejamento estratégico. 
Figura 5: ERP Contribui para Avaliação de Orçamento

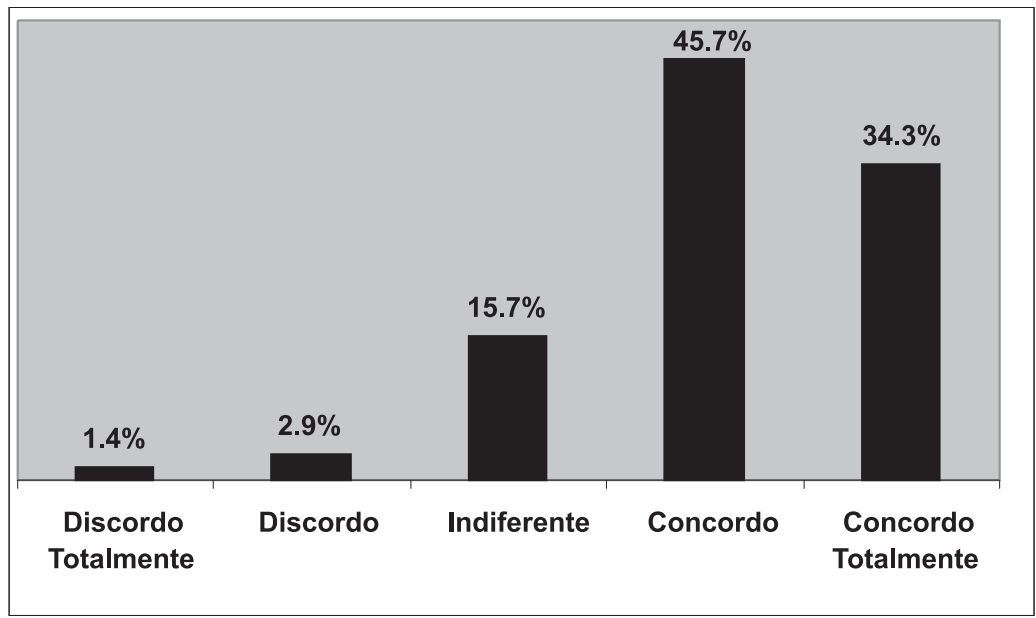

Quando questionados se o ERP ajuda a aumentar a margem de lucro da empresa, 52,9\% dos respondentes concordam com a afirmativa (vide Quadro 7), embora $37,1 \%$ se mostrem indiferentes nessa questão. Poston e Grabisk (2000) investigaram o impacto dos sistemas ERP sobre o desempenho organizacional (relação custos sobre receitas), identificando que, por um lado, empresas que adotaram o sistema tiveram redução no número de funcionários e aumento de receitas; mas, por outro, tiveram aumento do percentual de custos sobre receitas, apesar da diminuição de custos com pessoal e com otimização/automatização de processos. De acordo com os autores, outros custos passaram a existir, como contratação de pessoal especializado em ERP e ajustes finos que continuaram a ocorrer após o início da operação do sistema. Quanto à contribuição do ERP para o aumento da participação de mercado da empresa, $41,4 \%$ dos respondentes mostram-se indiferentes e somente 31,4\% deles concordam com alguma contribuição do sistema nesse sentido. Novamente os posicionamentos dividem-se, quando a questão é a contribuição do ERP com relação ao mercado da empresa.

\section{Quadro 7: O ERP Contribui para Aumentar a Margem de Lucro da Empresa}

\begin{tabular}{|l|l|l|}
\hline ERP x Margem de Lucro & Qt. cit. & Freq. \\
\hline Discordo Totalmente & 4 & $5.7 \%$ \\
\hline Discordo & 3 & $4.3 \%$ \\
\hline Indiferente & 26 & $37.1 \%$ \\
\hline Concordo & 28 & $40.0 \%$ \\
\hline Concordo Totalmente & 9 & $12.9 \%$ \\
\hline TOTAL OBS. & 70 & $100 \%$ \\
\hline
\end{tabular}


Ainda assim, cabe considerar que em relação a este bloco (eficiência e eficácia organizacional), o ERP demonstra ser ferramenta que agrega valor a vários aspectos relacionados à gestão, como pode ser visto pelas questões analisadas.

Bloco 7 - Eficiência interorganizacional. Integração organizacional é conceito chave, quando se trata de ERP. Primeiramente se buscou levantar se o sistema melhora o padrão de comunicação entre unidades organizacionais de diferentes regiões: 85,7\% dos respondentes concordam com essa afirmação, o que destaca a contribuição do ERP para a integração organizacional. Da mesma forma, 88,6\% concordam que o ERP ajuda a coordenar as atividades da empresa regionalmente, nacionalmente ou globalmente. Esse sempre foi um dos grandes apelos dos sistemas ERP, no sentido de integrar atividades realizadas entre unidades organizacionais de diferentes regiões.

A integração, desta vez com clientes e fornecedores, comprova-se novamente como ponto forte do ERP, quando 64,3\% dos respondentes afirmam que ele contribui para a coordenação das atividades com clientes e fornecedores (vide Quadro 8). Os respondentes (65,8\%) também afirmam que o ERP ajuda a agregar mais informações aos produtos e serviços da empresa (vide Figura 6).

Desta forma, os sistemas ERP se confirmam como facilitadores da integração interorganizacional e entre unidades distintas de uma mesma corporação, conforme aponta o referencial teórico corrente.

\section{Quadro 8: ERP Contribui para a Coordenação Junto a Clientes/Fornecedores}

\begin{tabular}{|l|c|c|}
\hline $\begin{array}{c}\text { ERP x Coordenação } \\
\text { Clientes/fornecedores }\end{array}$ & Qt. citações & Frequência \\
\hline Discordo totalmente & 0 & $0.0 \%$ \\
\hline Discordo & 2 & $2.9 \%$ \\
\hline Indiferente & 23 & $32.9 \%$ \\
\hline Concordo & 32 & $45.7 \%$ \\
\hline Concordo Plenamente & 13 & $18.6 \%$ \\
\hline TOTAL & $\mathbf{7 0}$ & $\mathbf{1 0 0} \%$ \\
\hline
\end{tabular}


Figura 6: ERP Permite à Empresa Agregar mais Informações aos Produtos/Serviços

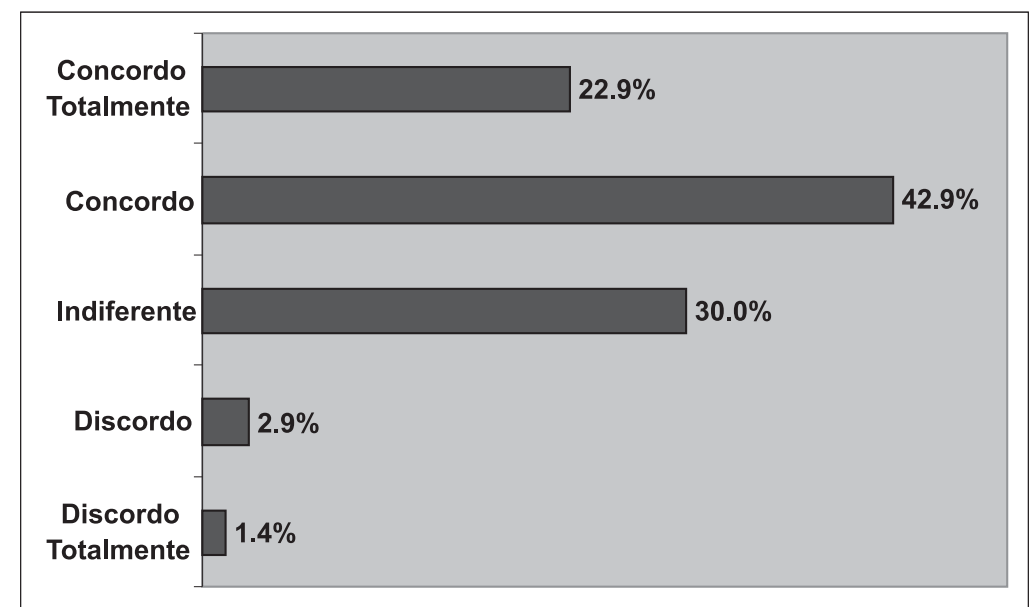

\section{Diferenças nos Resultados de Acordo com as Características das Organizações Pesquisadas}

Investigando-se os resultados mais a fundo, procurou-se descobrir primeiramente se o impacto dos sistemas ERP nas variáveis estratégicas poderia ser diferenciado de acordo com o setor ao qual pertence a organização. Ao se realizar o cruzamento de todas as 34 questões escalares com a variável setor, apenas três questões apresentaram diferença significativa nas médias das respostas (foi aplicado o teste t, com p=0.05). São elas: [Q10] - O ERP ajuda a monitorar a qualidade dos produtos e serviços recebidos dos fornecedores; [Q20] - O ERP ajuda a melhorar a produtividade do trabalho por meio da automação; [Q21] - O ERP ajuda a melhorar a utilização do maquinário. (veja os resultados encontrados no Quadro 9).

\section{Quadro 9: Diferenças nas Médias das Respostas de acordo com o Setor}

\begin{tabular}{|c|c|c|c|}
\hline & Q10- Monit. Fornec. & Q20- Prod./automação & Q21- Produção \\
\hline Indústria & 3.98 & 3.78 & 3.51 \\
\hline Comércio & 4.07 & 4.29 & 3.36 \\
\hline Serviços & 2.57 & 3.71 & 2.57 \\
\hline TOTAL & 3.86 & 3.87 & 3.39 \\
\hline
\end{tabular}


Como pode ser visto, as empresas do setor Serviços (muito embora sejam minoria na amostra, 7 em 70), ao contrário das demais, tendem a discordar que o ERP ajude a monitorar a qualidade dos produtos e serviços recebidos dos fornecedores [Q10]. Cabe investigar melhor se isso se deve à configuração dos sistemas ERP para o setor Serviços ou se a natureza das atividades da empresa, que envolvem elementos muitas vezes pouco tangíveis, tornam difícil o monitoramento da qualidade dos produtos e serviços recebidos dos fornecedores. Da mesma forma, as empresas do setor Serviços tendem mais fortemente a discordar que o ERP ajude a melhorar a utilização do maquinário [Q21]. Novamente cabe investigar melhor se isso se deve à configuração do sistema ou às características próprias do setor, no qual maquinário em geral não é o recurso mais importante, uma vez que serviços são mais dependentes de pessoas.

Já o setor Comércio foi o que mais concordou com a afirmativa de que o ERP ajuda a melhorar a produtividade do trabalho por meio da automação [Q 20]. De fato, na indústria, grandes avanços de automatização do trabalho vem sendo feitos há décadas, mas o mesmo não ocorria no Comércio.

Não foram encontradas diferenças significativas em relação ao impacto do ERP de acordo com o tamanho das organizações ou com o tempo de adoção. Muito embora se tenham realizado análises mais sofisticadas, utilizando técnicas como a Análise de Correspondência (Greenacre e Blasius, 1994), essas análises apenas confirmaram os resultados aqui apresentados, não trazendo novos elementos ou relações.

\section{Conclusões}

O Quadro 10 apresenta um resumo dos principais resultados encontrados pela pesquisa. Em síntese, eles revelam poucas contribuições do sistema ERP sobre as variáveis estratégicas Clientes e Consumidores, Rivalidade Competitiva e Mercado. O ERP demonstra agregar valor em relação à variável Fornecedores (relação, monitoramento etc.) e à variável Produção (ganhos de produtividade, escala no uso de software etc.). Ele oferece também importantes contribuições para a Eficácia Organizacional e especialmente para a Eficiência Interorganizacional, facilitando a gestão, integração e comunicação entre diferentes unidades organizacionais e com outras organizações. 


\section{Quadro 10: Variáveis Estratégicas e o Impacto dos Sistemas ERP}

\begin{tabular}{|c|c|}
\hline \begin{tabular}{|l} 
VARIÁVEL \\
ESTRATÉGICA
\end{tabular} & IMPACTO DO ERP \\
\hline $\begin{array}{c}\text { Clientes e } \\
\text { Consumidores }\end{array}$ & $\begin{array}{l}\text { - Não contribui para a disponibilização do banco de dados da empresa aos clientes } \\
\text { - } \quad \text { Ajuda a empresa a prover suporte administrativo aos clientes }\end{array}$ \\
\hline $\begin{array}{c}\text { Rivalidade } \\
\text { Competititiva }\end{array}$ & $\begin{array}{l}\text { - Não foi identificada uma contribuição direta na investida contra competidores ou } \\
\text { no sentido de contribuir para se oferecer produtos/serviços não imitáveis } \\
\text { - Não é visto como facilitador do processo concorrencial }\end{array}$ \\
\hline dores & $\begin{array}{l}\text { - Colabora para o aumento do poder de barganha da empresa junto aos seus } \\
\text { fornecedores } \\
\text { - Não apresenta contribuições significativas em facilitar aos fornecedores o acesso } \\
\text { aos pedidos da empresa } \\
\text { - Ajuda a reduzir a incerteza de lead time } \\
\text { - Contribui para se encontrar novas alternativas de fornecedores } \\
\text { - Ajuda nas decisões relativas a produzir x comprar determinado insumo. } \\
\text { Ajuda a monitorar a qualidade dos produtos e serviços recebidos dos } \\
\text { fornecedores* }\end{array}$ \\
\hline & $\begin{array}{l}\text { - Não foi identificada nenhuma contribuição significativa do sistema para a } \\
\text { previsão das tendências de mercado } \\
\text { - Contribui para maior precisão na previsão de vendas da empresa } \\
\text { - Não foi identificada contribuição significativa no sentido de ajudar a empresa a } \\
\text { antecipar melhor as necessidades do cliente } \\
\text { - Não foi identificada contribuição significativa no sentido de obter a lealdade dos } \\
\text { - clientes } \\
\text { - Coño contribui para a redução dos custos com marketing na empresa } \\
\text { Contribui para a eficiência competitiva da empresa }\end{array}$ \\
\hline $\begin{array}{r}\text { Prod } \\
\text { (estrutur } \\
\text { capa }\end{array}$ & $\begin{array}{l}\text { - Não demonstra contribuição significativa no processo de projetar novos produtos, } \\
\text { ou para reduzir o custo de modificar ou adicionar características aos } \\
\text { produtos/serviços existentes } \\
\text { - Ajuda a melhorar o nível de produção } \\
\text { - Ajuda a melhorar a produtividade do trabalho por meio da automação* } \\
\text { - Ajuda a melhorar a utilização do maquinário * } \\
\text { - Oferece ganhos por economia de escala no uso de software, mas não tanto no uso } \\
\text { de hardware }\end{array}$ \\
\hline $\begin{array}{c}\text { Eficiência e Eficácia } \\
\text { Organizacional }\end{array}$ & $\begin{array}{l}\text { - } \quad \text { Ajuda a melhorar o processo e o conteúdo das decisões } \\
\text { - } \quad \text { Pelhora as reuniões e discussões internas } \\
\text { - Contribuita melhor coordenação entre as áreas funcionais na empresa } \\
\text { - Melhora o planejamento estratégóico } \\
\text { - Ajuda a aumentar a margem de lucro da empresa } \\
\text { - Não apresenta contribuições significativas para o aumento da participação de } \\
\text { mercado da empresa }\end{array}$ \\
\hline $\begin{array}{c}\text { Eficiência } \\
\text { interorganizacional }\end{array}$ & $\begin{array}{l}\text { - Melhora o padrão de comunicação entre unidades organizacionais de diferentes } \\
\text { regiões } \\
\text { - Ajuda a coordenar a atividade da empresa regionalmente, nacionalmente ou } \\
\text { globalmente } \\
\text { - Contribui para a coordenação das atividades com clientes e fornecedores } \\
\text { - Ajuda a agregar mais informações aos produtos e serviços da empresa }\end{array}$ \\
\hline
\end{tabular}


Entretanto, para atender a variáveis estratégicas relacionadas ao ambiente externo da organização (mercado, concorrentes, clientes/consumidores) concluise que é necessária a complementaridade de outros sistemas. Um estudo publicado pelo Gartner Group (Bond et al., 2000) prevê que em 2004, 80\% das empresas que implantaram o ERP irão continuar investindo em melhorias de seus sistemas, principalmente por meio da implementação de novas funcionalidades.

Romeo (2001) aponta que, para que o ERP possa realmente servir como canal de informação para os esforços de e-business e ampliação dos canais de informação (externas e internas) são necessárias melhorias associadas à implementação de aplicações que o complementam, como, por exemplo, o DW (Data Warehouse), CRM (Customer Relationship Management), SCM (Supply Chain Management), BI (Business Intelligence), KM (Knowledge Management) e e-procurement. Essas tecnologias são normalmente associadas ao chamado ERP II, um ERP ampliado, capaz de se interligar a outros sistemas para integrar ações entre parceiros de negócios, abandonando o enfoque interno do ERP e tornando-o passível de utilização nos processos externos à organização, centrando-o na Web (Bond et al., 2000; Genovese, 2001).

Quanto a pesquisas futuras, tem-se uma série de indicações de temas pertinentes em relação aos sistemas ERP. O primeiro deles diz respeito à continuidade dos estudos sobre os resultados obtidos com a adoção dessa tecnologia, especialmente a avaliação quantitativa de resultados financeiros. Outra tendência é o estudo da utilização dos sistemas ERP em contextos não industriais. Serviços, educação, saúde e outros setores específicos merecem ser estudados. Pesquisas sobre a relação e-business-ERP são igualmente válidas, pois atualmente são poucos os referenciais de efetiva qualidade e profundidade a respeito desse tema. Outra tendência é a utilização de sistemas ERP via dispositivos móveis, tema sobre o qual praticamente não existe referencial acadêmico. Novos modelos de Terceirização e ASP (Application Service Providers) também são importantes, assim como ERP via software livre. Outra linha de pesquisa diz respeito à utilização dos sistemas ERP como plataforma para sistemas de BI (Business Intelligence), Datamining e Informação Executiva, ainda não esgotada na literatura. Da mesma forma, pesquisas sobre a avaliação do impacto da TI ainda são pertinentes, pois mesmo um modelo testado e validado como o de Mahmood e Soon (1991) teve de ser adaptado para esta pesquisa, verificando-se diferenças culturais no entendimento de alguns termos de negócio, no contexto brasileiro, durante os pré-testes do instrumento utilizado. 
ReferênCias Bibliográficas

BAKOS, J. Y.;

TREACY, M.

Information technology and corporate strategy: a research perspective. MIS Quarterly, p. 107-119, June 1986.

BARROS, F.

Reestruturação no mercado de software de gestão, 2003. Disponível em: <http:// www.computerworld.com.br> Acesso em: 06 fev. 2003.

BERGAMASCHI, S.;

REINHARD, N.

Implementação de sistemas para gestão empresarial. In: ENCONTRO ANUAL DA ANPAD, 24., 2000, Florianópolis. Anais... Rio de Janeiro: ANPAD, 2000. 1 CD-ROM.

BERNROIDER, E.;

$\mathrm{KOCH}, \mathrm{S}$.

Decision making for ERP investments from the perspective of organizational impact-preliminary results from an empirical study. In: AMERICAS CONFERENCE ON INFORMATION SYSTEMS, 5., 1999, [S.l.]. Proceedings... [S.l.: s.n.], 1999. 1 CD-ROM.

\section{BLOOMBERG NEWS.}

Novo lance na guerra dos softwares. Gazeta Mercantil, Porto Alegre, 23 jul. 2003, p. B-13.
BOND, B.;

GENOVESE, Y.;

MIKLOVIC, D.

ERP is dead - long live ERP II.

Gartner Group Research Note, Strategic Planning Assumption, 04 Oct. 2000.

CALDAS, M.; WOOD, T.

Modas e modismos em gestão: pesquisa exploratória sobre adoção e implementação de ERP. In: ENCONTRO ANUAL DA ANPAD, 23., 1999, Foz do Iguaçu. Anais... Rio de Janeiro: ANPAD, 1999. 1 CD-ROM.

CASH, J. I.;

KONSYNSKI, B.

R. Is redraws competitive boundaries. Harvard Business Review, v. 2, n. 63, p. 134-142, 1985.

CÉSAR, R.

SSA prepara unificação com Baan no Brasil, 2003. Disponível em: $<$ http://www.computerworld.com.br> Acesso em: 29 set. 2003.

CLEMONS, E.

Information systems for sustainable competitive advantage. Information \& Management, p. 131-136, Nov. 1986. 
CORRÊA, H. C.;

GIANESI, I.;

CAON, M.

Planejamento, programação e controle da produção. São Paulo: Atlas, 1999.

DAVENPORT, T. H.

Mission critical: realizing the promise of enterprise systems. Boston: Harvard Business School, 2000.

DELLOITE CONSULTING.

ERP's second wave. Research

Report, n. 24, p. 1998.

ESTEVES, J.;

PASTOR, J.

Enterprise resource planning systems research: an annotated bibliography. Communications of AIS, v. 7, Aug. 2001.

EXAME.

As 500 melhores e maiores empresas do Brasil. São Paulo: Abril, jun. 2000.

FINK, A.

The survey handbook. London: Sage Publications, 1995.

GENOVESE, Y.

Characteristics of ERP II in collaborative commerce. Gartner Group Research Note, 30 May 2001.

GOBARA, R.

Brasil é oportunidade para

ERP, 2003. Disponível em: <http://www.itweb.com.br. > Acesso em: 01 set. 2003.

GREENACRE, M.;

BLASIUS J.

Correspondence analysis in the social sciences. London:

Academic Press, 1994.

HEDMAN, J.;

BORELL, A.

The impact of enterprise resource planning systems on organizational effectiveness: an artifact evaluation. In: NAH, F. F. Enterprise resource planning solutions \& management. Hershey: IRM Press, 2002. p.125-139.

HITT, L.;

BRYJOLFSSON, E.

Productivity, business profitability and consumer surplus: three different measures of IT value. MIS Quartely, p. 121-142, June 1996.

HYPOLITO, C. M.;

PAMPLONA, E.

Principais problemas na implantação de um sistema integrado de gestão. In: ENCONTRO NACIONAL DE ENGENHARIA DE PRODUÇÃO, 20., 2000, São Paulo. Anais... São Paulo: ENEGEP, 2000. 1 CD-ROM.

KUMAR, K.;

HILLEGERSBERG, J. V.

ERP experiences and evolution. Communications of the ACM, v. 43, n. 4, p. 23-26, Apr. 2000. 
LUFTMAN, J. N.;

LEWIS, P. R.;

OLDACH, S. H.

Transforming the enterprise: the alignment of business and information technology strategies.

IBM Systems Journal, v. 32, n. 1, p. 198-221, 1983.

MAHMOOD, M. A;

SOON, S. K.

A comprehensive model for measuring the potential impact of information technology on organizational strategic variables.

Decision Sciences, v. 22, p. 869897, 1991.

MCFARLAN, F. W.

Information technology changes the way you compete. Harvard Business Review, v. 3, n. 62, p. 98-103, 1984.

MENDES, J. V.;

ESCRIVÃO FILHO, E.

Sistema integrado de gestão (ERP) em empresas de médio porte: um confronto entre o referencial teórico e a prática empresarial. In: ENCONTRO ANUAL DA ANPAD, 25., 2001, Campinas. Anais... Rio de Janeiro: ANPAD, 2001. 1 CD-ROM.

MESQUITA, R. V.

Yankee analisa a nova PeopleSoft, 2003. Disponível em: <http://www.itweb.com.br> Acesso em: 21 set. 2003.

NEVES, M.

Sistemas integrados de gestão em uma perspectiva estratégica. In: ENCONTRO NACIONAL DE ENGENHARIA DE PRODUÇÃO, 19., 2000, São Paulo. Anais... São Paulo: ENEGEP, 2000. 1 CD-ROM.

PARSONS, G. L.

Information technology: a new competitive weapon. Sloan Management Review, p. 107119, Fall 1983.

PORTER, M.

Estratégia competitiva: técnicas para análise de indústrias e da concorrência. Rio de Janeiro: Campus, 1980.

POSTON, R.;

GRABISK, S.

The impact of enterprise resource planning systems on firm performance. In: INTERNATIONAL CONFERENCE ON INFORMATION SYSTEMS, 21., 2000, [S.l.]. Proceedings... Disponível em: <http://www.aisnet.org> Acesso em: 21 out. 2003.

RANGANATHAN, C.; SAMARAH, I.

Enterprise resource planning systems and firm value: an event study analysis. In: I N T E R N A T I O N A L CONFERENCE ON INFORMATION SYSTEMS, 22., 2001, [S.l.]. Proceedings... Disponível em: <http:// www.aisnet.org> Acesso em: 21 out. 2003. 
ROMEO, J.

ERP: on the rise again. Network Computing, v. 12, n. 19, Sept. 2001.

SACCOL, A. Z. et al.

Sistemas ERP e seu impacto sobre variáveis estratégicas de grandes empresas no Brasil. In: SOUZA, C. A.; SACCOL, A. Z. (Orgs.). Sistemas ERP no Brasil: teoria e casos. São Paulo: Atlas, 2003.

\section{SACCOL, A. Z.;}

MACADAR, M. A.;

SOARES, R. O.

Organizational change related to the use of ERP in Brazilian enterprises. In: BALAS ANNUAL CONFERENCE, 2001, San Diego. Proceedings... San Diego: BALAS, 2001. 1CD-ROM.

SEDERA, D.;

GABLE, G.;

CHAN, T.

Measuring enterprise systems success: a preliminary model. In: AMERICAS CONFERENCE ON INFORMATION SYSTEMS, 9., 2003, [S.l.]. Proceedings... Disponível em: <http://aisnet.org.> Acesso em: 21 out. 2003.

\section{SHIELDS, M.}

E-business and ERP: rapid implementation and project planning. New York: John Wiley \& Sons, 2001.
SOUZA, C. A.;

SACCOL, A. Z. (Orgs.).

Sistemas ERP no Brasil: teoria e casos. São Paulo: Atlas, 2003.

SOUZA, C. A.;

ZWICKER, R.

Big-bang, small-bangs ou fases: estudo dos aspectos relacionados ao modo de início de operação de sistemas ERP. In: ENCONTRO ANUAL DA ANPAD, 26., 2002, Salvador. Anais... Rio de Janeiro: ANPAD, 2002. 1 CD-ROM.

ERP system's life cycle: findings and recommendations from a multiple-case study in Brazilian companies. In: BALAS ANNUAL CONFERENCE, 2001, San Diego. Proceedings... San Diego: BALAS, 2001. 1 CD-ROM.

Implementação de sistemas ERP: um estudo de casos comparados. In: ENCONTRO ANUAL DA ANPAD, 24., 2000, Florianópolis. Anais... Rio de Janeiro: ANPAD, 2000. 1 CD-ROM.

WOOD JR., T.;

CALDAS, $\mathrm{M}$.

The part and the whole: reductionism and complex thinking in ERP systems implementation. In: ENCONTRO ANUAL DA ANPAD, 24., 2000, Florianópolis. Anais... Rio de Janeiro: ANPAD, 2000. 1 CD-ROM. 